\title{
An update on the management of glandular fever (infectious mononucleosis) and its sequelae caused by Epstein-Barr virus (HHV-4): new and emerging treatment strategies
}

\author{
This article was published in the following Dove Press journal: \\ Virus Adaptation and Treatment \\ 23 September 2010 \\ Number of times this article has been viewed
}

\author{
A Martin Lerner' \\ Safedin $\mathrm{H}^{\text {Beqaj }^{2}}$ \\ Ken Gill ${ }^{3}$ \\ James Edington ${ }^{3}$ \\ James T Fitzgerald ${ }^{4}$ \\ Robert G Deeter ${ }^{5}$ \\ 'Department of Medicine, William \\ Beaumont Hospital, Royal Oak, MI, \\ USA; ${ }^{2}$ DCL Medical Laboratories, \\ Indianapolis, IN, USA; \\ ${ }^{3}$ The Dr A Martin Lerner, Chronic \\ Fatigue Syndrome Foundation, \\ Beverly Hills, MI, USA; ${ }^{4}$ Department \\ of Medical Education, University of \\ Michigan, Medical School, Ann Arbor, \\ MI, USA; ${ }^{5}$ Hematology-Oncology, \\ Global Health Economics, Amgen Inc, \\ Thousand Oaks, CA, USA
}

Purpose: Beginning in 1993 at a single chronic fatigue syndrome (CFS) treatment center, we began studies that demonstrate Epstein-Barr virus (EBV) nonpermissive replication. In the most recent study performed, EBV nonpermissive replication is the cause of $28.3 \%$ of 106 consecutive CFS cases, and is etiologic with human cytomegalovirus (HCMV) and/or human herpes virus 6 (HHV-6) as a coinfection in an additional $52.8 \%$ of CFS cases. Therefore, EBV is causally involved in $81 \%$ of cases of CFS. Further, EBV CFS is effectively treated with long-term valacyclovir. Coinfection HCMV and HHV-6 CFS requires valganciclovir with valacyclovir.

Patients and results: The validated Energy Index Point Score ${ }^{\circledR}\left(\right.$ EIPS $\left.^{\circledR}\right)$ monitors severity of CFS illness and its recovery. A specific CFS diagnostic panel identifies EBV CFS subsets. Four separate EBV CFS therapeutic studies of several hundred CFS patients describe valacyclovir administration and long-term patient recovery. With valacyclovir, serum EBV titers (EBV, early antigen (diffuse); EBV, viral capsid antigen, immunoglobulin M); 24-hour electrocardiography Holter monitors; and cardiac dynamic studies improve.

Conclusion: Nonpermissive EBV infection is causal in a significant proportion of CFS cases. EBV CFS is safely and effectively treated with long-term valacyclovir.

Keywords: valacyclovir treatment, chronic fatigue syndrome, Epstein-Barr virus, EIPS, Energy Index Point Score

\section{Introduction}

Drüsenfieber (glandular fever) was first described by Pfeifer $^{1}$ and, later, by Sprunt and Evans. ${ }^{1,2}$ Paul and Bunnell ${ }^{3}$ discovered the heterophile antibody response identifying clinical infectious mononucleosis (IM). Epstein-Barr virus (EBV) was recognized by Epstein et al. ${ }^{4}$ Henle et $\mathrm{al}^{5}$ associated this virus with IM. EBV was subsequently shown to induce immortality in tissue cultures and, thus, a tumor-producing potential was indicated. ${ }^{6}$ The overwhelming majority of cases of glandular fever are due to EBV, and this virus has an almost uniform human prevalence. ${ }^{7}$ Human herpesvirus 6 (HHV-6), adenovirus, toxoplasmosis, human immunodeficiency virus, and human cytomegalovirus (HCMV [HHV-5]), however, may cause IM-like illnesses. ${ }^{8}$ A distinguishing characteristic of EBV IM is its soft grey exudative pharyngitis. Here we review EBV IM and outline sequelae caused by nonpermissive EBV replication. We report successful treatment of these sequelae with valacyclovir. All studies were performed with valtrex (Glaxo Welcome); these results do not represent use of generic valacyclovir.
Correspondence: A Martin Lerner 32804 Pierce Rd, Beverly Hills, MI 48025, USA

Tel +l 2485409866

Fax +l 2485400139

Email amartinlerner@yahoo.com 
Nonpermissive EBV multiplication is identified in subsets of the chronic fatigue syndrome (CFS).

EBV (HHV-4) is a gamma herpesvirus with a doublestranded DNA genome of $184 \mathrm{Kbp}$, a surrounding 162 protein capsomeres and internal tegument proteins. The virus is enclosed in a lipid layer with glycoprotein spikes (Figure 1). ${ }^{9-11}$ Viral latency indicative of nonreplicating, nonchromosomally integrated EBV is a circular closed intranuclear episome. The principal cell of EBV latency is the memory B cell. ${ }^{12,13}$ Complete virus replication is the end point of primary and reactivated infection with host cell necrosis, and, a both specific and nonspecific inflammatory immune response. Type A and Type B EBV strains have been identified, the latter being prevalent in Africa, particularly among immunocompromised patients. ${ }^{11,14}$

EBV infection follows saliva-transfer by kissing or sexual intercourse. Infants and children experience an asymptomatic, or mild innocuous EBV infection, but adolescents in the age 15-25 have the highest incidence of IM in the United States, United Kingdom, Europe, and Japan. ${ }^{7,15}$ A complex of 3 EBV virus glycoproteins, $\mathrm{gH}, \mathrm{gL}$, and gp42 is essential for intracellular entry. After attaching to C3D (CR2) receptor in oropharyngeal squamous epithelial cells, EBV replicates in salivary glands and T and B lymphocytes. ${ }^{13,16}$ During the viremia of explosive primary infection, liver, thyroid, brain,
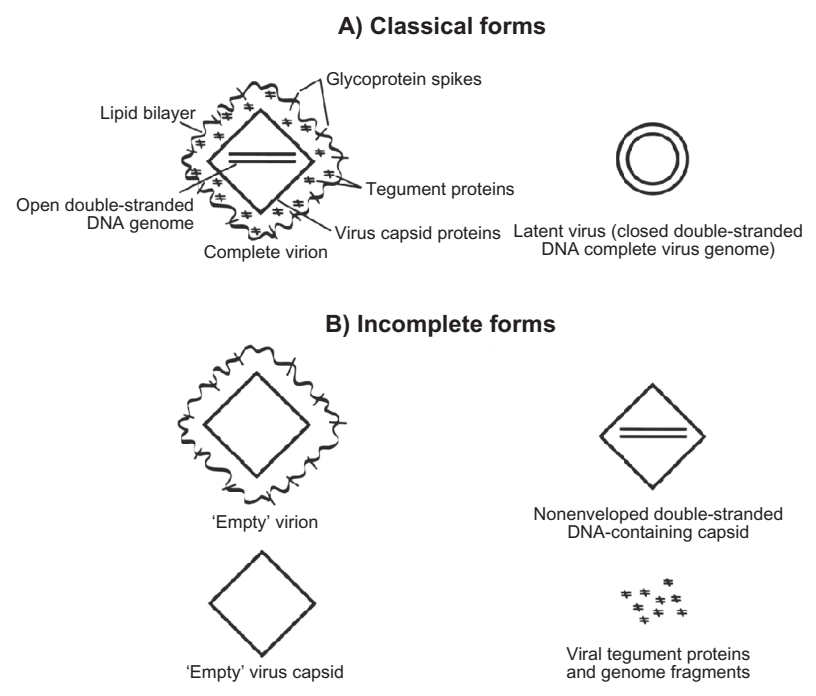

Figure I Some forms of herpesviruses.

Notes: Possible herpesvirus forms, complete and incomplete are shown. The "complete" herpesvirus virion (EBV, a gamma herpesvirus) is shown with component parts: (I) lipid bilayer, (2) glycoprotein spikes, (3) tegument proteins, (4) virus capsid proteins, and (5) open double-stranded DNA complete virus genome. Latent herpesvirus is the complete genome as a closed nonintegrated inactive circular episome situated in the nucleus of an infected cell (eg, EBV; B lymphocyte). "Incomplete" unassembled herpesvirus forms are empty virion (no DNA genome); nonenveloped double-stranded DNA-containing capsid; empty virus capsid and viral tegument proteins and genome fragments.

Copyright (C) 2004, reproduced with permission from Lerner AM, Beqaj SH, Deeter RG, et al. IgM serum antibodies to Epstein-Barr virus are uniquely present in a subset of patients with chronic fatigue syndrome. In Vivo. 2004; 18:10I-106. meninges, myocardium, and pericardium may be affected. EBV may also be acquired by blood transfusion. ${ }^{17}$

With IM EBV infection, approximately $0.5 \%$ of the total lymphocyte population is infected. Fever, prostration, sore throat, often with a dusky soft exudate upon the tonsillar rings, painful cervical lymphadenopathy, tender left upper quadrant splenomegaly, and atypical lymphocytosis distinguish glandular fever. Hospitalization of an acutely ill IM patient, usually for less than a week, may be necessary. Clinical recovery over $1-3$ months is usual. There are no seasonal, sex, ethnic, or genetic associations of IM. The mean age of onset of IM is 18.4 years. A long-intermittent EBV virus presence in the pharynx in 15\%-20\% well seropositive adults may follow. African Burkitt lymphoma, B-cell malignant and T-cell malignant lymphomas, and nasopharyngeal cancer are closely associated with EBV infection. ${ }^{7,16} \mathrm{EBV}$ is a common associate of hemophagocytic lymphohistiocytosis. In male patients with $\mathrm{X}$-linked lymphoproliferative syndrome, primary EBV infection may result in severe or fatal IM. ${ }^{18}$

\section{Traditional longstanding therapy}

IM and its complications cause significant morbidity including the long-term disability of CFS. ${ }^{19-23}$ There is no currently accepted treatment. A short course of oral corticosteroids, 1-7 days of oral prednisone, $10 \mathrm{mg} 4$ times a day for IM has advocates because the duration of fever and pharyngeal symptoms are shortened, but all agree that when upper airway obstruction accompanies IM, short-term (5 days) high dose intravenous corticosteroids (80 mg solumedrol per day) and tracheostomy may be life saving. ${ }^{24}$ Corticosteroids are not recommended for treatment of uncomplicated IM, and their use has been associated with increases in complications. ${ }^{16}$ Complications of IM include myopericarditis, meningitis, encephalomyelitis, peripheral neuropathy, hepatitis, thyroiditis and subset CFS. ${ }^{23}$

\section{Persistent both permissive and nonpermissive EBV infection with CFS and treatment}

Hoshino et $\mathrm{al}^{25}$ showed that long-term valacyclovir decreases the number of infected B cells, and in theory might eradicate EBV from the body if the patient is not reinfected. We have initiated a CFS specific diagnostic panel identifying EBV, HCMV, and HHV-6 subsets of CFS. ${ }^{23}$ The validated Energy Index Point Score ${ }^{\circledR}$ EIPS $^{\circledR}$ monitors severity of CFS illness and its progress during treatments with valacyclovir. The presence of serum immunoglobulin (Ig) M antibody to EBV viral capsid antigen (VCA) indicates "active" EBV 
infection. ${ }^{21,26}$ EBV VCA IgM serum antibody appears approximately 1 month after primary infection, and disappears in $95 \%$ of cases within 6 months to 1 year. ${ }^{27}$ An absence of serum EBV IgG VCA antibody indicates susceptibility to $\mathrm{EBV}$, and no prior infection. Both $\mathrm{D}$ (diffuse) and $\mathrm{R}$ (restricted) components of EBV early antigen (EA) indicate abortive nonpermissive incomplete virus replication to about the first 50 early genes of sequential early and late genes in the cascade of the complete genome (Figure 1). CFS patients are unable to prevent nonpermissive EBV replication which subsequently leads to dysregulation of cellular metabolism, and, ultimately, apoptosis without EBV DNA polymerase positivity or antigenemia. ${ }^{28}$ Late in primary IM, a presence of serum EBV nuclear antibody (NA) reflects multiple late gene antigens. ${ }^{26}$ Serum EBV NA and EBV VCA IgG antibodies are long lasting. We review the studies supporting valacyclovir treatment of EBV subset CFS.

\section{Pharmacology, pharmacokinetics, metabolism, distribution, and excretion of valacyclovir}

Acyclovir (9-[(12-hydroxyl-ethoxy) methyl 7-9 H guanine]) is an acyclic guanine nucleoside. Cellular uptake of serum acyclovir is facilitated by viral thymidine kinase. Acyclovir's unique safety relies on its 200 times greater affinity for viral thymidine kinase than for the mammalian enzyme. Intracellular enzymes convert acyclovir monophosphate to acyclovir triphosphate which is " $40-100$-fold higher in virally infected than uninfected cells." The triphosphate of acyclovir is incorporated into viral DNA where it acts as a DNA chain terminator binding to viral DNA leading to irreversible viral inactivation (Figure 2). ${ }^{29-52}$

Valacyclovir is the L-valylester of acyclovir. Valacyclovir is a prodrug of the active compound acyclovir. After oral administration, valacyclovir is converted rapidly to acyclovir by first-pass intestinal and hepatic metabolism through enzymatic hydrolysis. Approximately 2 hours after $1,000 \mathrm{mg}$ valacyclovir, the usual CFS dosage for a $70 \mathrm{~kg}$ CFS patient, acyclovir serum concentrations average $5-6 \mu \mathrm{g} / \mathrm{mL}$, but peak acyclovir levels, after absorption of $1 \mathrm{gm}$ of valacyclovir, vary from $7-21 \mu \mathrm{g} / \mathrm{mL} .{ }^{39}$ After oral administration of valacyclovir, the bioavailability of acyclovir increases 3-5-fold to approximately $70 \%$ of the administered dosage. Serum acyclovir is eliminated in the urine by glomerular filtration and tubular secretion. Acyclovir distributes widely in body fluids including vesicular fluid, aqueous humor, and cerebrospinal fluid. Compared with plasma, salivary concentrations are low and vaginal concentrations vary widely. Acyclovir is concentrated in breast
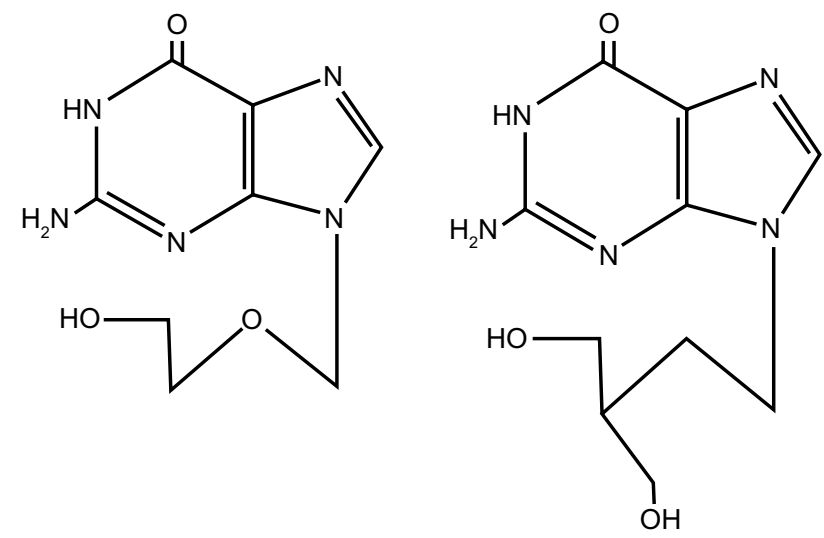

Acyclovir

Penciclovir

milk, amniotic fluid, and placenta. Percutaneous absorption of valacyclovir and acyclovir is low. In adults with normal renal function, the mean plasma $t \frac{1}{2}$ elimination of acyclovir is about 2 hours 30 minutes, with a range of $1.5-6$ hours. The $t \frac{1}{2}$ of elimination of acyclovir in anuric patients is prolonged to 20 hours. Less than $15 \%$ of administered valacyclovir is excreted as 9-carboxy-methoxy-methylguanine. Serum acyclovir is $9 \%-22 \%$ protein-bound. Renal concentrations of acyclovir are $10 \times$ simultaneous plasma concentrations. Central nervous system concentrations are $25 \%-70 \%$ plasma concentrations. Probenecid and cimetidine reduce renal clearance by $32 \%$, presumably by inhibiting tubular secretion of acyclovir. The pharmacokinetics of acyclovir in children older than 1 year is similar to adults.

The acyclovir in vitro $\mathrm{ID}_{50}$ for HSV-1 and 2 is $0.003-$ $2.2 \mu \mathrm{g} / \mathrm{mL}$. The acyclovir ID $_{50}$ for varicella-zoster virus (VZV) is $0.8-4.0 \mu \mathrm{g} / \mathrm{mL}$, and for EBV it is $0.8-4.0 \mu \mathrm{g} / \mathrm{mL}$. However, the acyclovir $\mathrm{ID}_{50}$ for HCMV is greater than $20 \mu \mathrm{g} / \mathrm{mL}$, and for HHV-6 the acyclovir $\mathrm{ID}_{50}$ is $4.4-14.4 \mu \mathrm{g} / \mathrm{mL}$. Acyclovir concentrations of $50-100 \mu \mathrm{g} / \mathrm{mL}$ in serum are without adverse effects. Mammalian cell growth is inhibited by $>300 \mu \mathrm{g} / \mathrm{mL}$. These unique pharmacologic findings account for valacyclovir's safety, and allow long-term administration to patients. Valacyclovir is effective therapy in HSV-1, HSV-2, and VZV infections. Valacyclovir may occasionally be associated with headache, nausea, or diarrhea.

Acyclovir nephrotoxicity (formation of acyclovir renal stones) and its potential nervous system toxicity are the results of patient dehydration or renal insufficiency. In immunocompromised patients, thrombocytopenia may be seen, but thrombocytopenia has not been seen in healthy or CFS patients. When EBV CFS patients are well hydrated ( $\geq 6,8$ ounce glasses of water/day), thrombocytopenia, neurologic complications, and nephrotoxicity are not present. 
When $1 \mathrm{gm}$ of valacyclovir is given $(14.3 \mathrm{mg} / \mathrm{kg})$ every 6 hours, a benign increase in mean corpuscular volume of red blood cells is regularly observed, but there is no anemia. ${ }^{39}$ Food increases valacyclovir bioavailability, and valacyclovir is best given after meals. When CFS patients weigh over $79.5 \mathrm{~kg}, 1.5 \mathrm{gm}$ valacyclovir is given every 6 hours. Cimetidine (400 mg every 12 hours) and/or probenecid (500 mg every 12 hours) which inhibit acyclovir tubular secretion may be given to increase serum acyclovir levels..$^{29,30}$ During valacyclovir administration, CFS patients are seen by a physician every 6 weeks or more often, if needed..$^{23}$ At each visit, a normal complete blood count, platelet count, aminotransferases, and urinalysis are required to continue care.

\section{Famciclovir (famvir)}

Famciclovir (penciclovir) is the diethyl ester prodrug of 6-deoxy penciclovir and lacks antiviral activity. The active moiety penciclovir (9-[14-hydroxy-3-hydroxymethyl but-1-y1]) guanine is an acyclic guanine nucleoside ana$\log$ that is phosphorylated by viral thymidine kinase to triphosphate analogs. The $\mathrm{ID}_{50}$ of penciclovir is within 2 -fold of acyclovir. Penciclovir triphosphate is a competitive inhibitor of viral DNA polymerase. It is $1 / 100$ inhibitor of viral DNA polymerase as acyclovir triphosphate, but it is present in much higher intracellular concentrations, and for more prolonged periods in infected cells than is acyclovir triphosphate. Famciclovir has similar in vitro activity to that of acyclovir vs EBV. In assays measuring infectious virus production, viral antigen expression, and viral DNA synthesis, penciclovir inhibits the productive replication cycle of EBV. The EBV $\mathrm{ID}_{50}$ of penciclovir and acyclovir are $2.3 \pm 0.8$ and $2.2 \pm 0.6 \mathrm{mg} / \mathrm{mL}$, respectively ${ }^{51}$ (Figure 2). ${ }^{48-51}$

The $t \frac{1}{2}$ of penciclovir triphosphate is $7-20$ hours. Its antiviral effect is prolonged. It is not a chain terminator, but does inhibit DNA elongation. Acyclovir-resistant HSV strains are cross-resistant to penciclovir. Famciclovir is absorbed well, and converted rapidly to penciclovir by deacetylation of the side chain, and further oxidation of the purine ring. Following oral administration of famciclovir, the bioavailability of penciclovir is $65 \%-77 \%$. Food slows absorption of famciclovir, but does not reduce its bioavailability. After 250-500 mg doses, peak penciclovir plasma concentrations are $1.6-33 \mu \mathrm{g} / \mathrm{mL}$. After intravenous penciclovir $10 \mathrm{mg} / \mathrm{kg}$, peak plasma concentration is $12 \mu \mathrm{g} / \mathrm{mL}$. The plasma $t \frac{1 / 2}{2}$ is 2 hours, and over $90 \%$ is excreted in the urine by glomerular filtration, and, probably, active tubular secretion. After oral administration of famciclovir, approximately $10 \%$ is excreted in feces. Uncommon side effects of famciclovir are headache, diarrhea, nausea, urticaria, rash, and hallucinations.

\section{Valganciclovir}

Ganciclovir and its orally available prodrug valganciclovir inhibit EBV in vitro $\left(\mathrm{ID}_{50}=0.05 \mu \mathrm{g} / \mathrm{mL}\right) .{ }^{52}$ Ganciclovir inhibits human progenitor cells and lymphocyte blastogenesis. Therefore, ganciclovir's hepatotoxic, neutropenic, thrombocytopenic, and malignant potentials have led us to not use ganciclovir in EBV infections. Valganciclovir is highly active vs HCMV and HHV-6, $\mathrm{ID}_{50}=0.2-2.8 \mu \mathrm{g} / \mathrm{mL}$. Coinfections with EBV, HCMV, and HHV-6 are common in CFS illness. ${ }^{23,53-55}$ Valganciclovir is the first-therapeutic choice vs HCMV and HHV-6 CFS infections.

\section{Efficacy of valacyclovir in EBV subset CFS}

To our knowledge, valacyclovir at 4-6 gm per day had not been previously reported until this work was first described. ${ }^{39}$ We obtained permission from the US Food and Drug Administration in 1996. The guideline of therapy is a serum acyclovir value above the EBV $\mathrm{ID}_{50}$ for $>75 \%$ of the day. Several hundred patients have now been treated without serious side effects. With similar protocol, 10-15 patients received famciclovir for portions of their EBV CFS treatment. Four to six grams every 24 hours of famciclovir are also well tolerated. We have studied the etiology, diagnosis, and treatment of CFS since $1990 .{ }^{23}$ International criteria for CFS diagnosis are employed.$^{19}$ Over the course of these studies, we developed a specific diagnostic panel which selectively identifies EBV CFS patients allowing subset specific appropriate therapy (Table 1). With this specific diagnostic CFS panel, we subdivide CFS into "Group A herpesvirus CFS, EBV with/without HCMV, and HHV-6 with no other confections." "Group B CFS is similar to Group A herpesvirus CFS, but with other coinfections.” This report concerns EBV single-virus CFS and its diagnosis and treatment. However further details concerning Group A and Group B CFS subsets will be noted elsewhere. ${ }^{23}$

The point prevalence of EBV, HCMV, and HHV-6 herpesviruses among Group A CFS patients was determined at this CFS treatment center during a 6-year systematic review of 106 Group A CFS patients treated with group and subset-directed antiviral medicines for $\geq 6$ months (2001-2007). ${ }^{23}$ Data were captured on a predefined work sheet with $>7,000$ office visits and $>35,000$ fields of information entered into a MS Access database. Among these 106 Group A CFS patients, there were 30 CFS patients (28.3\%) with single EBV persistent infection and no HCMV or HHV-6, and no other coinfections. There 
Table I Diagnostic Panel: ${ }^{a}$ Epstein-Barr virus subset chronic fatigue syndrome

\begin{tabular}{ll}
\hline Positives & Negatives \\
\hline International criteria, CFS & Cytomegalovirus, IgG human \\
24-hour ECG monitor, oscillating & herpesvirus 6, IgG \\
T-wave flats and inversions, & Borrelia burgdorferi, Western Blot, \\
tachycardia, at rest & ELISA, IgM, and IgG \\
Epstein-Barr virus, early antigen & Babesia microti, IgG Anaplasma \\
(diffuse) total antibody \pm viral & phagocytophila, IgG \\
capsid antigen, IgM & Mycoplasma pneumoniae, IgG \\
& Antistreptolysin $O,<400$ \\
\hline
\end{tabular}

Note: ${ }^{a}$ For specific details, see text, especially antigens used.

Abbreviations: CFS, chronic fatigue syndrome; ECG, electrocardiogram.

were, additionally, 56 of the 106 Group A CFS patients with EBV and coinfections with HCMV and/or HHV-6. Therefore, " $81 \%$ of the CFS patients had EBV infections." CFS patients with EBV single virus infections were treated with valacyclovir. CFS patients with EBV and HCMV/HHV-6 infections received valacyclovir and valganciclovir.

\section{The Energy Index Point Score}

The validated EIPS is a critical element in the CFS diagnostic panel to assess the health status of each CFS patient and monitor care during treatments. ${ }^{56}$ At patient visits in 4-6 week intervals, the EIPS is determined by agreement of patient and physician. An EIPS 0-5 is diagnostic of CFS. ${ }^{19,56}$ At EIPS values 6-10, patients no longer have CFS. Effect size is used to determine practical changes in EIPS. A small change in EIPS value is an effect size of 0.5. An effect size of 0.8 is large. ${ }^{57} \mathrm{~A}$ CFS patient is considered a "responder" to antiviral treatment if the change in EIPS effect size is $\geq 1$. A CFS patient is a "nonresponder" to antiviral treatment if the effect size is $\leq 1$ after 1 year of antiviral therapy (Figure 3 ). ${ }^{23}$

\section{Demographics of CFS patients with EBV persistent infection}

Clinical presentations of CFS patients in subsets of Group A and Group B CFS are indistinguishable and were not recognized early on (Table 2). The mean age of 98 consecutive CFS patients (1987-1994) was 42.3 years. They were $87 \%$ women. Patients were ill a mean of 12.2 months when first seen. They were previously well, healthy, nonsmokers $(16 \%$ smoked cigarettes); did not have diabetes mellitus ( $0 \%$ diabetes mellitus); were not obese ( $6 \%$ were obese); were not hyperlipidemic ( $12 \%$ total cholesterol $>250 \mathrm{mg} \%$ ); were not hypertensive (3\% systolic BP $>140 \mathrm{~mm} / \mathrm{Hg})$; were not alcoholic $(8 \%>45$ cc alcohol per day); and were not psychiatric patients before onset of illness (11\% antidepressants at first visit). They were incapacitated, nonfunctional with "chest pain", dull and aching, coming on usually at the end of the day when fatigue was maximum. They had palpitations at rest, were lightheaded/syncope, and had diffuse muscle aches. Sore throats were often present and we observed pathognomonic hard white plaques at the bases of Waldeyer tonsillar crypts only in patients with EBV subset CFS. These hard white plaques are in the same Waldeyer tonsillar ring as the soft exudates of IM. Low-grade daily fevers were sometimes present, and tender cervical lymph nodes were common. ${ }^{58}$

Valacyclovir was begun at 1 gm every 6 hours. If patients were obese, the dose of valacyclovir was increased to $1.5 \mathrm{gm}$ every 6 hours. If patients are small, valacyclovir was decreased proportionally to body weight. A Jarisch-Herxheimer response with worsening of symptoms, and, paradoxically decreasing EIPS continuing for 2-6 weeks was a good prognostic omen. ${ }^{59,60}$ At these "worsening" times, CBC, AST, ALT, Cr, and urinalysis remained normal. The CFS patient then remained at baseline EIPS. An increasing EIPS and decreasing symptoms were apparent at the fifth to sixth month of continuing valacyclovir. ${ }^{23}$ As valacyclovir was continued, an EIPS 7 was attained, and activities of normal living were again usual.

Any alcohol may cause chest (cardiac) pain and worsen CFS. Alcohol is interdicted until the CFS patient reaches an EIPS of 8, and then, cautiously in small amounts. Alcohol intolerance may continue after recovery. Exercise, too early in CFS recovery, may worsen CFS. Exercise is also prohibited until EIPS 7 is achieved. At EIPS 8, light exercise is cautiously begun. Valacyclovir dose then is decreased to $1 \mathrm{gm}$ 2 times a day and continued for 6-12 weeks and stopped. Approximately $20 \%$ of EBV CFS patients require maintenance valacyclovir to prevent clinical relapse.

At baseline, initial evaluation of CFS patients resting electrocardiograms (ECGs) may be normal, but 24-hour Holter monitor (HM) shows T-wave inversions or flattening. Bicycle protocol MUGA stress studies of myocardial dynamics are done when standard resting ECG is abnormal. ${ }^{58}$ Myocardial perfusion studies are uniformly normal in CFS patients excluding coronary artery disease (technetium myoview dipyridamole myocardial perfusion imaging). However, 11.6\% of the CFS at rest/stress radionuclide ventriculography demonstrated abnormal cardiac wall motion (rest), and 24.1\% had abnormal rest/stress studies. Infero/apical and septal wall motion abnormalities and apical tardokinesis confirmed EBV primary myocardial disease. Cardiac biopsy with electron microscopy demonstrated myofiber disarray without cellular infiltrates. ${ }^{61-64}$ Focal interstitial fibrosis, myofiber drop-out, myofiber hypertrophy, and perimysial fat infiltration were present. EBV myocarditis, a complication of IM is documented. ${ }^{65-68}$ 


\section{To physicians caring for patients with CFS:}

The Energy Index Point Score ${ }^{\circledR}$ (EIPS ${ }^{\circledR}$ ) chart provides the severity of patient fatigue.

A change in EIPS level of one is a large significant change. The EIPS level is determined by agreement of physician and patient with the EIPS chart easily available for viewing at out-patient visits. As the EIPS level increases, CFS symptoms lessen and disappear.

How to use the EIPS system in four easy steps:

1) Post the EIPS chart in examining room

2) Ask patient to evaluate his/her level of activity based upon the prior two weeks

3) Question the patient's EIPS evaluation

4) Record and track the EIPS level. Report every 6-12 weeks.

\begin{tabular}{|c|c|}
\hline 0 & Bed-ridden, up to bathroom only \\
\hline 1 & Out of bed $30-60$ minutes a day (sitting in chair is out of bed) \\
\hline 2 & Out of bed sitting, standing, walking 1-2 hours per day \\
\hline 3 & Out of bed sitting, standing, walking $2-4$ hours per day \\
\hline 4 & Out of bed sitting, standing, walking $4-6$ hours per day \\
\hline \multirow[t]{2}{*}{5} & Perform with difficulty sedentary job 40 hours a week, daily naps \\
\hline & R E C O V E R Y \\
\hline 6 & $\begin{array}{l}\text { Daily naps in bed, may maintain a } 40 \text { hour sedentary work week plus light, } \\
\text { limited housekeeping and/or social activities }\end{array}$ \\
\hline 7 & $\begin{array}{l}\text { No naps in bed. Up 7:00 a.m. to 9:00 p.m. Able to work a sedentary job plus } \\
\text { light housekeeping }\end{array}$ \\
\hline 8 & Full sedentary workweek, no naps, some social activities plus light exercise \\
\hline 9 & $\begin{array}{l}\text { Same as } 8 \text { above plus exercise approximately } 1 / 2 \text { to } 2 / 3 \text { normal without } \\
\text { excessive fatigue, awakens next morning refreshed }\end{array}$ \\
\hline 10 & Normal \\
\hline
\end{tabular}

Figure 3 Energy Index Point Score ${ }^{\circledR}$ (EIPS ${ }^{\circledR}$ ). A functional capacity measurement tool for chronic fatigue syndrome (CFS) patients.

(C) 1998-2008 Dr A Martin Lerner CFS Treatment Center Energy Index Point Score ${ }^{\circledR}$ (EIPS ${ }^{\circledR}$ ) is registered in the US patent office of the Dr A Martin Lerner CFS Treatment Center. All rights reserved. This document may be copied for use by physicians and patients, but may not be modified, sold, or distributed promotionally in any form without express written permission. For more information visit: www.treatmentcenterforcfs.com.

Abbreviation: CFS, chronic fatigue syndrome.

\section{4-hour Holter monitor studies}

The CFS specific EBV diagnostic panel was used throughout (Table 1). Standard 12-lead ECG plus a 24-hour ECG (HM) and baseline serologic studies are done. The standard resting ECG is usually normal. ${ }^{19,61}$ The greater the duration of CFS illness before valacyclovir treatment, the more likely it is that baseline standard ECG is abnormal. ${ }^{64}$ Among 106 Group A CFS patients, 92 patients (88.5\%) had abnormal baseline 24-hour ECG monitors (HM): 77 patients (74\%) had abnormal oscillating T-wave flattening, 46 patients (44.2\%) had abnormal oscillating T-wave inversions, and 47 patients $(44.5 \%)$ had tachycardias at rest. The abnormal HMs in EBV CFS is a biomarker of CFS cardiac disease. ${ }^{23}$ Palpitations, syncope, and positive tilt-table testing accompany abnormal HMs (Figure 4).

In a consecutive case series (1991-1993), HM recordings were compared.$^{64}$ They were $67 \mathrm{CFS}$ patients and 78 non-CFS patients matched for age, place, time, and an absence of confounding medical diseases. Two noninvolved cardiologists unaware of the patient diagnosis read the HMs. The 2 comparative groups, $\mathrm{CFS}$ and non-CFS patients were similar: age CFS, 40 years; age non-CFS, 36 years. CFS patients were $87 \%$ women, but non-CFS patients were $61 \%$ women $(P<0.05)$. CFS patients had $61 \%$ abnormal oscillating T-wave inversions and $96 \%$ abnormal T-wave flattening; non-CFS patients had $34 \%$ abnormal T-wave inversions and 71\% T-wave flattening 
Table 2 Demographic characteristics in 98 chronic fatigue syndrome patients in Birmingham, Michigan 1987-1994

\begin{tabular}{|c|c|c|c|c|}
\hline Variable & $\begin{array}{l}\text { All CFS } \\
\text { patients }^{\mathrm{a}}(\mathbf{9 8 )}\end{array}$ & $\begin{array}{l}\text { CFS patients with } \\
\text { abnormal stress } \\
\text { MUGAS (2I) }\end{array}$ & $\begin{array}{l}\text { CFS patients with } \\
\text { normal stress } \\
\text { MUGAS (66) }\end{array}$ & Significance \\
\hline Age, years, mean & $42.3 \pm 10.6$ & $45.2 \pm 11.0$ & $41.6 \pm 9.5$ & NS \\
\hline Women, \% & $87 \%$ & $81 \%$ & $91 \%$ & NS \\
\hline $\begin{array}{l}\text { Duration of CFS } \\
\text { (months) }\end{array}$ & $|2.2 \pm| \mid .3(80)$ & $9.6 \pm 6.3(15)$ & $12.6 \pm$ II.I (65) & NS \\
\hline $\begin{array}{l}\text { Other medical } \\
\text { diagnoses, \% }\end{array}$ & $21 \%$ & $32 \%$ & $15 \%$ & NS \\
\hline Diabetes mellitus, \% & $0 \%$ & & & NS \\
\hline $\begin{array}{l}\text { Hypertensive vascular } \\
\text { disease, \% }\end{array}$ & $3 \%$ & $0 \%$ & $4 \%$ & NS \\
\hline $\begin{array}{l}\text { Total cholesterol } \\
>250 \mathrm{mg} \%\end{array}$ & $12 \%$ & $19 \%$ & $8 \%$ & NS \\
\hline Obesity, \% & $6 \%$ & $6 \%$ & $8 \%$ & NS \\
\hline Cigarette smokers & $16 \%$ & $20 \%$ & $13 \%$ & NS \\
\hline Alcohol, \% & & & & NS \\
\hline Nonuser & $43 \%$ & $40 \%$ & $44 \%$ & \\
\hline I or $2 /$ mos $^{b}$ & $37 \%$ & $45 \%$ & $36 \%$ & \\
\hline I or $2 / w k$ & $12 \%$ & $5 \%$ & $13 \%$ & \\
\hline I of $2 / d$ & $7 \%$ & $5 \%$ & $7 \%$ & \\
\hline $3+/ d$ & $1 \%$ & $5 \%$ & $0 \%$ & \\
\hline & & $0 \%$ & $15 \%$ & \\
\hline $\begin{array}{l}\text { Antidepressants at } \\
\text { first visit }\end{array}$ & $11 \%$ & $0 \%$ & $15 \%$ & NS \\
\hline
\end{tabular}

Notes: ${ }^{\mathrm{T}}$ The number of CFS patients evaluated is listed in parenthesis; ' $\mathrm{O}$ ne jigger equals $45 \mathrm{cc}$ alcoholic beverage.

Copyright @ 2004, reprinted with permission from Lerner AM, Beqaj SH, Deeter RG, et al. IgM serum antibodies to Epstein-Barr virus are uniquely present in a subset of patients with chronic fatigue syndrome. In Vivo. 2004;18:101-106.

Abbreviations: CFS, chronic fatigue syndrome; NS, not significant.

$(P<0.01)$. The sensitivity of oscillating T-wave flattening in CFS patients at HM was 0.96 . The sensitivity of T-wave inversion was 0.61 . The specificity of T-wave flattening was 0.29 and the specificity of T-wave inversion was 0.66. An absence of abnormal oscillating T-waves made the diagnosis CFS unlikely. Hypertensive vascular disease without coronary

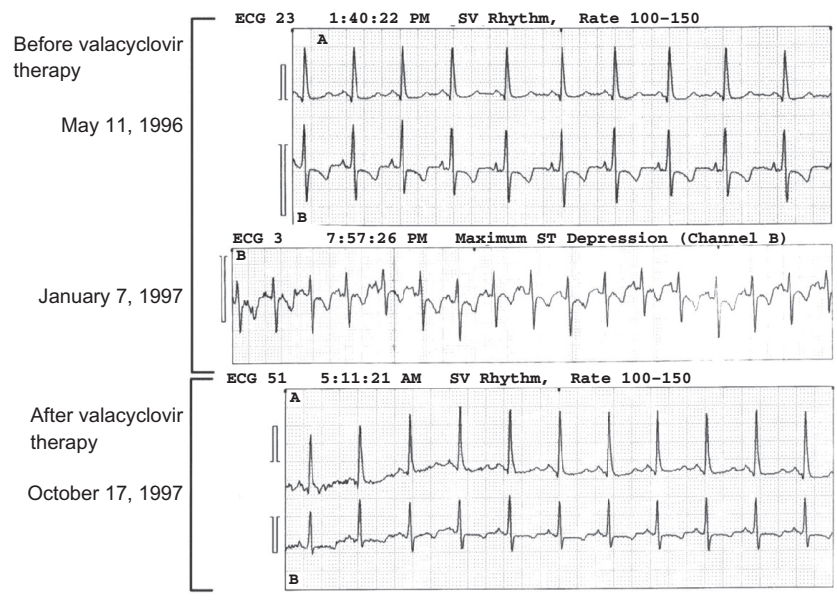

Figure 4 Sequential Holter monitoring in a 3I-year-old woman with CFS. Copyright (C) 2002, Prous Science. Reproduced with permission from Lerner AM, Beqaj SH, Deeter RG, et al. A six-month trial of valacyclovir in the Epstein-Barr virus subset of chronic fatigue syndrome: improvement in left ventricular function. Drugs Today. 2002;38(8):549-56I. Abbreviation: CFS, chronic fatigue syndrome. artery disease was the usual cause of T-wave abnormalities in the 78 non-CFS patients. ${ }^{64}$

\section{Diagnostic serologic panel EBV CFS panel}

Serologic studies diagnostic of EBV subset CFS are EBV, EA(D), and/or EBV VCA IgM indicating current active EBV replication. ${ }^{23}$ EBV CFS patients may have elevated serum viral capsid IgM antibody titers (VCA) and/or elevated serum titers to EBV EA(D). ${ }^{21,23,39}$ The EBV VCA antigen p-18 peptide (Diasorin, Stillwater, Minn) is used. In EBV single virus CFS negative studies are: antistreptolysin $\mathrm{O}(\mathrm{ASO})<400$; Borrelia burgdorferi, ELISA and western blot IgM and IgG (Lab Corp, Dublin, Ohio); HCMV IgM and IgG to strain AD69; HCMV p52 (UL 44) recombinant protein; CM2 (UL44 and part UL57 recombinant proteins; Diasorin); IgG HHV-6; IgG Mycoplasma pneumoniae, Babesia microti, and Anaplasma phagocytophila. An initial conundrum in CFS diagnosis was: a healthy person may have an elevated EBV (EA, D), but this same test in a CFS patient diagnosed by this specific diagnostic panel indicates EBV CFS. We hypothesize the healthy individual with an elevated serum EBV (EA) serum titer has EBV nonpermissive replication to only the first 30 early EBV genes, which may not be a dysregulating factor of cellular metabolism, whereas the CFS 
patient with this same result has an EBV replication cascade to middle or late genes beyond the approximate 50th linear gene of the genome necessary for CFS illness. ${ }^{20,21}$ Indeed, concerning HCMV CFS, HCMV replication to at least the 50th gene adjacent to DNA polymerase gene of HCMV (UL44, UL57, HCMV, p52, and CM2 antigens) are present. ${ }^{69,70}$ This nonpermissive viral CFS hypothesis further predicts mRNA to early EBV genes are present in circulating mononuclear cells in the bloods of EBV CFS patients (Table 1). ${ }^{23}$

\section{Efficacy of valacyclovir in Group}

\section{A EBV single virus subset CFS}

\section{Treatment with valacyclovir}

Case studies utilizing valacyclovir were reported in 2002 , 2004, 2007, and 2010. ${ }^{23,39,71,72}$

Study 1 (Figure 5): Nineteen EBV CFS patients who had been ill for less than 1 year were given valacyclovir for 6 months. ${ }^{39}$ Ten single-virus EBV subset CFS patients who had negative HCMV IgG serum antibody titers improved from an initial mean EIPS value 4.1 to an EIPS value $7.0(P<0.0075)$. Five of these single EBV CFS patients (no HCMV serum IgG antibody) had positive EBV, VCA, IgM titers, and 8 of these EBV CFS single virus patients had elevated EBV (EA) serum titers. Nine CFS patients with both EBV and HCMV elevated serum antibody titers did "not" improve when treated with valacyclovir. Their initial EIPS was 4.1 and after 6-month EIPS was 4.6. At the completion of the randomized double-blinded trial, at 6 months, all patients were given open valacyclovir and all single-virus EBV subset CFS patients then improved to an EIPS of $>$ or equal to 7 . Seven of the total number of 19 CFS patients in this study had positive serum EBV, VCA, IgM titers.

Six of these single-EBV CFS patients had baseline and 6-month dynamic nuclear MUGA left ventricular ejection fraction (EF) studies. Their initial mean EF was 59\%

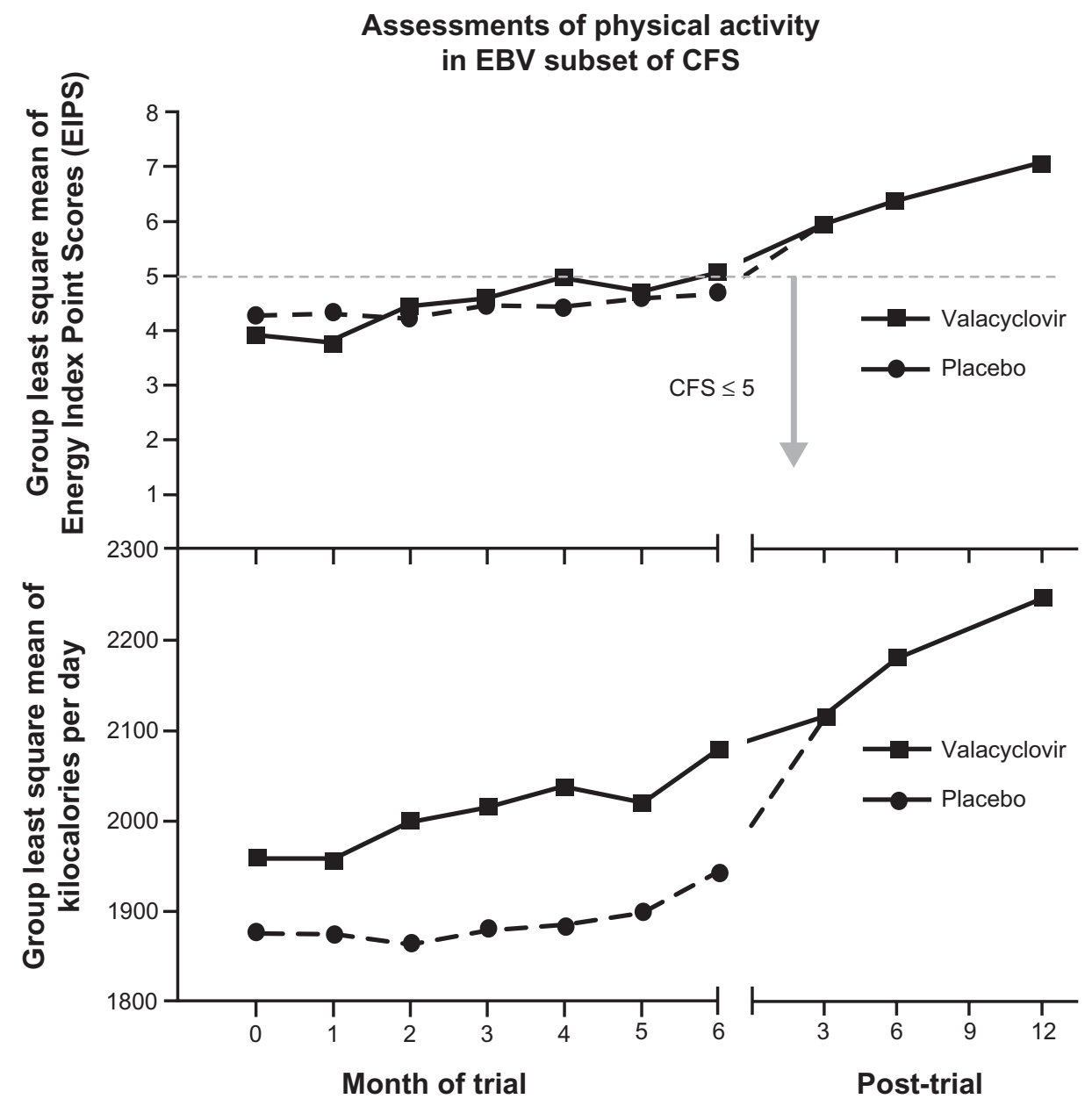

Figure 5 Assessments of physical activity in EBV subset of CFS.

Copyright (C) 2007, reproduced with permission from Lerner AM, Beqaj SH, Deeter RJ, et al. Valacyclovir treatment in Epstein-Barr virus subset chronic fatigue syndrome with long-term thirty-six month follow-up. In Vivo. 2007;21:707-7I4.

Abbreviations: EBV, Epstein-Barr virus; CFS, chronic fatigue syndrome. 
(normal $\geq 55 \%$ ), but the final mean $\mathrm{EF}$ was $70 \%$, an increase of $11(18.9 \%, P=0.007)$. We conclude from this initial case study that $10 \mathrm{CFS}$ patients with single-virus EBV subset CFS infections improved after 6 months of valacyclovir. CFS symptoms disappeared; tachycardias and associated syncope disappeared, and left ventricular EFs improved. Nine CFS patients with EBV/HCMV subset coinfections did not improve.

Study 2: In 2004, a second case study was completed. ${ }^{71}$ This was a double-blinded, placebo-controlled, crossover study of patients with CFS in patients with elevated HCMV serum IgG serum antibody titers. Eleven of these CFS patients were followed for 18 months. Their mean age was 42.7 years, and mean CFS duration prior to treatment was 35.1 months. At completion of 6-months intravenous ganciclovir, no increase in EIPS values occurred.

At this stage of the study, patients with coinfection elevated EBV antibody titers (VCA IgM or EBV EA) were given valacyclovir. At baseline, their EIPS value was 3.5. At 6 months of intravenous ganciclovir, patients with serologic evidence additionally to HCMV had EBV coinfections with elevated EBV EA serum antibody titers (these patients with EBV/HCMV coinfections) were given valacyclovir. At 18 months, the mean EIPS value was 6.1. CFS symptoms improved. These results, again, are consistent with valacyclovir benefit to patients with Group A EBV HCMV coinfection CFS. Both valacyclovir and valganciclovir were necessary for these patients recovery.

Study 3 (Figure 5, post-trial): ${ }^{72} \mathrm{~A}$ blinded-random third case study was a 6-month placebo-controlled trial of valacyclovir in 27 Group A CFS EBV-single virus subset. At completion of 6 months, 14 patients and 13 controls were given open valacyclovir, and they were then followed for a total study-length of 36 months. After 6 months, 14 CFS patients receiving valacyclovir experienced an increased mean least square EIPS value +1.12 (122 kcal/day), whereas the 13 placebo-control similar patients increased +0.42 EIPS value (65 kcal/day). At the 6 -month assessments, sinus tachycardias decreased, and abnormal cardiac wall motion improved only in valacyclovir-treated EBV CFS patients. Serum antibody titers to EBV VCA IgM decreased concordant with administration of valacyclovir. EIPS values increases then progressively improved to a mean value of 7.0 for all 27 patients (now all receiving valacyclovir) at the 36-month assessments. A long-term benefit to all patients followed $(P<0.05)$.

Study 4: In this fourth case study (2010), 106 Group A CFS patients with single or multiple herpesvirus (EBV/HCMV/HHV-6) infection were followed from
2001 to $2007 .{ }^{23}$ Among these 106 Group A CFS patients, there were $30 \mathrm{EBV}$ single virus CFS patients. The EBV CFS single virus mean age at baseline was 43.1 years. Before beginning valacyclovir, these CFS patients had been ill for a mean of 3.06 years. They were 20 women and 10 men. The mean body mass index was $26.7 \mathrm{~kg} / \mathrm{m}^{2}$. The baseline mean EIPS value was 4.33 , but the mean for the last EIPS value was 6.28, a mean increase EIPS value of 1.95. While under treatment there were 10 patients that achieved EIPS values of 8-9, 7 patients that achieved EIPS values of 7-8, and 4 patients that achieved EIPS values of 6.0 .

\section{Safety and tolerability}

The goal of valacyclovir therapy is an EBV subset CFS patient who easily sustains normal activities of daily living with a stable EIPS value of $>7$. After achieving EIPS values of 7-8, full therapeutic valacyclovir continues for 3 further months. Valacyclovir is then decreased to $1 \mathrm{gm}$ twice daily. If the EIPS value remains stable 4-6 weeks later, valacyclovir is stopped. Approximately, 25\% of several hundred Group A CFS patients with EBV single virus require continuing valacyclovir. Approximately, 10\% of Group A CFS EBV single virus patients, further, require long-term full dosage valacyclovir to maintain EIPS value $>7$.

The cost of valacyclovir tablets for 1 gm every 6-hour regimen is $\$ 53.00$ per day or $\$ 1600.00$ per month. We have continued valacyclovir for 7 years without ill effects. Patient adherence to the 4 times daily dosing of valacyclovir is facilitated with explanation that little improvement occurs until the sixth month of treatment. Patients appreciate the good prognostic omen of the early Jarisch-Herxheimer response.

\section{Conclusions}

The EIPS value is an accurate metric to determine the severity of EBV CFS illness and monitor recovery. The spectrum of illness of glandular fever (IM) is extended to include longlasting disability with cardiomyopathy and persistent nonpermissive EBV replication, and a progressive incapacitation. The pathologic potential of EBV nonpermissive abortive replication is reported for the first time. A specific working EBV subset-directed diagnostic panel, and effective therapy for Group A EBV single virus subset CFS are outlined. Longterm pharmacokinetic effective dosing with valacyclovir is described. Valacyclovir may benefit patients of all ages with IM who are at risk for its severe complications including myocarditis, hepatitis, meningoencephalitis, peripheral neuritis, and thyroiditis. There are more than 800,000 patients with EBV single or coinfection CFS in the United States. ${ }^{73,74}$ 


\section{Addendum}

The recent association of CFS with the retrovirus XMRV is under evaluation. ${ }^{75}$ Likewise, EBV clearly dysregulates cellular pathways consistent with nonpermissive EBV replication postulated here for the major mechanism of CFS and contributing as well to the development of cancer. ${ }^{76}$

\section{Acknowledgments}

We acknowledge gratefully Deanna Mason, security officer, for these data and Deborah McNeilance, transcriptionist. We recognize and thank Ann Cavanagh, Communications Director at the Dr A Martin Lerner CFS Foundation for critical review of this manuscript.

\section{Disclosure}

Diagnostic and therapeutic methods reported here are the subject of issued patents and a pending patent application which are available for licensing. More information is available at: http://www.treatmentcenterforcfs.com/patents/index.html. The authors report no conflicts of interest in this work.

\section{References}

1. Pfeifer E, Drüsenfieber J. Kinderheil/Kd. 1889;29:257-264.

2. Sprunt TP, Evans FA. Mononuclear leukocytes reaction to acute infection (in infectious mononucleosis). Bull Johns Hopkins Hosp. 1920;31:410-417.

3. Paul JR, Bunnell WW. The presence of heterophile antibodies in infectious mononucleosis. Am J Med Sci. 1932;183:90-103.

4. Epstein MA, Achong HG, Barr YM. Virus particles in cultured lymphoblasts from Burkitt's lymphoma. Lancet. 1964;1:702-703.

5. Henle G, Henle W, Diehl V. Relation of Burkitt's tumor associated herpes-type virus to infectious mononucleosis. Proc Natl Assoc Sci US A. 1968;59:94-101.

6. Miller G, Lipman M. Release of infectious Epstein-Barr virus by transformed marmoset leucocytes. Proc Natl Acad Sci US A. 1973;70: 190-194.

7. Niederman JC, Evans AS. Epstein-Barr Virus. In: Evans AS, Kaslow RA, editors. Viral Infections of Humans: Epidemiology and Control. 4th ed. New York, London: Plenum Medical Book Company; 1997:253-284, Chap 10.

8. Klemola E, von Essen R, Henle G, Henle W. Infectious mononucleosislike disease with negative heterophile agglutination test. Clinical features in relation to Epstein-Barr virus and cytomegalovirus antibodies. J Infect Dis. 1970;121:608-614.

9. Roizman B. The family of herpes viridae: a brief introduction. In: Roizman B, Whitley RJ, Lopez C, editors. The Human Herpes Viruses. New York: Raven Press; 1993:1-10.

10. Robertson E, editor. Epstein-Barr Virus. Norfolk, England: Caister Academic Press; 2005:770.

11. Crawford H. Epstein-Barr virus. In: Zuckerman HJ, Banatvala JE, Pattison JR, editors. Principles and Practice of Clinical Virology. 4th ed. John Wiley \& Sons Ltd; 2001:117-140.

12. Hadinoto V, Shapiro M, Greenough TC, Sullivan John L, Uzuriaga K, Thorley-Lawson DavidA. On the dynamics of acute EBV infection and the pathogenesis of infectious mononucleosis. Blood. 2008;111: 1420-1427.

13. Borza CM, Hutt-Fletcher LM. Alternate replication in B cells and epithelial cells switches tropism of Epstein-Barr virus. Nat Med. 2002;8:594-599.

14. Tsai CH, Williams MV, Glaser R. Characterization of two monoclonal antibodies to Epstein-Barr virus diffuse study antigen which react to two different epitopes and have different biological function. $J$ Virol Methods. 1991;33(1-2):47-52.
15. Balfour HH Jr, Holman CJ, Hokanson KM, et al. A prospective clinical study of Epstein-Barr virus and host interactions during acute infectious mononucleosis. J Infect Dis. 2005;192:1505-1512.

16. Cohen JI. Epstein-Barr virus infections, including infectious mononucleosis. In: Kasper DL, Braunwald E, Fauci AS, Longo D, Hauser SL, editors. Harrison's Principles of Internal Medicine. 16th ed. McGraw Hill; 2005:1046-1049.

17. Henle W, Henle G, Harrison FS, et al. Antibody responses to Epstein-Barr virus and cytomegaloviruses after open-heart and other surgery. N Engl J Med. 1968;282:1068-1074.

18. Luzuriaga K, Sullivan JL. Infectious mononucleosis. $N$ Engl J Med. 2010;362:1993-1999.

19. Fukuda K, Straus SE, Hickie I, et al. The chronic fatigue syndrome: a comprehensive approach to its definition and study. International Chronic Fatigue Syndrome Study Group. Ann Intern Med. 1994;121: 953-959.

20. Lerner AM, Zervos M, Dworkin HJ, et al. A unified theory of the cause of the chronic fatigue syndrome. Infect Dis Clin Pract. 1997;63: 239-243.

21. Lerner AM, Beqaj SH, Deeter RG, et al. IgM serum antibodies to Epstein-Barr virus are uniquely present in a subset of patients with chronic fatigue syndrome. In Vivo. 2004;18:101-106.

22. Tobi M, Morag A, Ravid Z, et al. Prolonged atypical illness associated with serological evidence of persistent Epstein-Barr virus infection. Lancet. 1982;1:61-64.

23. Lerner AM, Beqaj S, Fitzgerald JT, et al. Subset-directed antiviral treatment of 142 herpesvirus patients with chronic fatigue syndrome. Virus Adapt Treat. 2010;2:1-11.

24. Tynell E, Aurelius E, Brandell A, et al. Acyclovir and prednisone treatment of acute infectious mononucleosis. A multicenter, double-blind, placebo-controlled study. J Infect Dis. 1996;174:324-331.

25. Hoshino Y, Katano H, Zou P, et al. Long-term administration of valacyclovir reduces the number of Epstein-Barr virus (EBV)-infected cells, but not the number of EBV DNA copies per B cell in healthy volunteers. $J$ Virol. 2009;83:11857-11861.

26. Henle W, Henle G, Horwitz CA. Epstein-Barr virus specific diagnostic tests in infectious mononucleosis. Human Pathol. 1974;5: 551-565.

27. Horwitz CA, Henle W, Henle G, et al. Long-term serologic follow-up of patients for Epstein-Barr virus after recovery from infectious mononucleosis. J Infect Dis. 1985;151:1150-1153.

28. Landolfo S, Gariglio G, Lembo D. The human cytomegalovirus. Pharmacol Ther. 2003;98:269-297.

29. Purifoy DJ, Beauchamp LM, de Miranda P, et al. Review of research leading to new anti-herpesvirus agents in clinical development: valacyclovir hydrochloride (256 U, the L-valyl ester of acyclovir) and $882 \mathrm{C}$, a specific agent for varicella zoster virus. J Med Virol. 1993;Suppl 1:139-145.

30. Weller S, Blum MR, Doucette M, et al. Pharmacokinetics of the acyclovir prodrug valacyclovir after escalating single- and multiple-dose administration to normal volunteers. Clin Pharmacol Ther. 1993;54: 595-605.

31. Emberg I, Andersson J. Acyclovir efficiently inhibits oropharyngeal excretion of Epstein-Barr virus in patients with acute infectious mononucleosis. J Gen Virol. 1986;67:2267-2272.

32. Pagano JS, Sixby JW, Lin JC. Acyclovir and Epstein-Barr virus infection. J Antimicrob Chemother. 1983;12:113-121.

33. Rolan PE, Maillott F, On NT, Posner J. The effects of Cimetidine and probenecid on the conversion of a valacyclovir ester of acyclovir $256 \mathrm{U}$ to acyclovir and acyclovir renal clearance in healthy volunteers. $\mathrm{Br} J$ Clin Pharmacol. 1993;35:533.

34. Laskin OL. Clinical pharmacokinetics of acyclovir. Clin Pharm. 1983;8: 187-201.

35. Laskin OL. Acyclovir pharmacology and clinical experience. Arch Intern Med. 1984;144:1241-1246.

36. Lycke J, Malmestrom C, Stahle L. Acyclovir levels in serum and cerebrospinal fluid after oral administration of valacyclovir. Antimicrob Agents Chemother. 2003;47:2438-2441.

37. Wagstaff AJ, Faulds D, Goa K Acyclovir. A reappraisal of its antiviral activity, pharmacokinetic properties and therapeutic efficacy. Drugs. 1994;47:153-205. 
38. Pagano JS, Data AK. Perspectives on interactions of acyclovir and Epstein-Barr and other herpesviruses. Am J Med. 1982;73:18-26.

39. Lerner AM, Beqaj SH, Deeter RG, et al. A six-month trial of valacyclovir in the Epstein-Barr virus subset of chronic fatigue syndrome: improvement in left ventricular function. Drugs Today. 2002;38(8):549-561.

40. Datta AK, Colby BM, Shaw JE, Pagano JS. Acyclovir inhibition of EpsteinBarr virus replication. Proc Natl Acad Sci U SA. 1980;77: 5163-5166.

41. Colby BM, Shaw JE, Elion GB, Pagano JS. Effect of acyclovir [9-(2hydroxyethoxymethyl)guanine] on Epstein-Barr virus DNA replication. J Virol. 1980;34:560-568.

42. Colby BM, Furman PA, Shaw JE, Elion GB, Pagano J. Phosphorylation of acyclovir [9-(2-hydroxyethoxymethyl)guanine] in Epstein-Barr virus-infected lymphoblastoid cell lines. J Virol. 1981;38:606-611.

43. St Clair MH, Furman PA, Lubbers CM, et al. Inhibition of cellular alpha and virally induced deoxyribonucleic acid polymerases by the triphosphates of acyclovir. Antimicrob Agents Chemother. 1980;18: 741-745.

44. Furman PA, de Miranda P, St Clair MH, et al. Metabolism of acyclovir in virus-infected and uninfected cells. Antimicrob Agents Chemother. 1981;20:518-524.

45. Torre D, Tambini R. Acyclovir for treatment of infectious mononucleosis: a meta-analysis. Scand J Infect Dis. 1999;31:543-547.

46. van der Horst C, Joncas J, Ahronheim G, et al. Lack of effect of peroral acyclovir for the treatment of acute infectious mononucleosis. $J$ Infect Dis. 1991;164:788-792.

47. Balfour H Jr, Hokanson KH, Schacherer R, et al. A virologic pilot study of valacyclovir in infectious mononucleosis. $J$ Clin Virol. 2007;39(1): 16-21.

48. Vere Hodge RA. Review: antiviral portraits series, number 3. Famciclovir and penciclovir. The mode of action of famciclovir including its conversion to penciclovir. Antivir Chem Chemother. 1993;4:67-84.

49. Boyd MR, Kern ER, Safrin S. Penciclovir: a review of its spectrum of activity, selectivity, and cross-resistance pattern. Antivir Chem Chemother. 1993;4:3-11.

50. Hayden FG. Antiviral drugs other than ante-retrovirals. In: Mandell GL, Bennett JE, Dolin R, editors. Principles and Practice of Infectious Disease. 5th ed. Philadelphia: Churchill Livingstone; 2000. p. 468-469. Penciclovir and Famciclovir.

51. Bacon TH, Boyd MR. Activity of penciclovir against Epstein-Barr virus. Antimicrob Agents Chemother. 1995;39(7):1599-1602.

52. Straus SE. Epstein-Barr virus and human herpesviruses 6 and 7. In: Gallasso GJ, Whitley RJ, Merigan TC, editors. Antiviral Agents and Human Viral Diseases. Lippincott-Rave Publishers; 708. Chap 18.

53. Komaroff AL. Is human herpesvirus- 6 a trigger for chronic fatigue syndrome? J Clin Virol. 2006;37:S39-S46.

54. Buchwald D, Cheney PR, Peterson DL, et al. A chronic illness characterized by fatigue, neurologic and immunologic disorders, and active herpesvirus type 6 infection. Ann Intern Med. 1992;116:103-113.

55. Agut $\mathrm{H}$, Collandre $\mathrm{H}$, Aubin T, et al. In vitro sensitivity of human herpesvirus-6 to antiviral drugs. Res In Virol. 1989;140:219-228.

56. Lerner Am, Beqaj SH, Fitzgerald JT. Validation of the Energy Index Point Score to serially measure degree of disability in patients with chronic fatigue syndrome. In Vivo. 2008;22:799-802.

57. Lerner AM, Zervos M, Dworkin HJ, et al. A new cardiomyopathy: a pilot study of intravenous ganciclovir in a subset of the chronic fatigue syndrome. In Dis In Clin Prac. 1997;16:110-117.
58. Lerner AM, Dworkin HJ, Sayyed T, et al. Prevalence of abnormal cardiac wall motion in the cardiomyopathy associated with incomplete multiplication of EBV and/or CMV in patients with chronic fatigue syndrome. In Vivo. 2004;18:417-424.

59. Jarisch A. Therapeutische Jersuche bei syphilis. Wien Med Wochenschr. $1895 ; 45: 721-742$.

60. Herxheimer K, Krause D. Uber eine bei syphilitischen vorkommende quecksilber-reaktion. Deutch Med Wochenschr. 1902;28:895-897.

61. Lerner AM, Lawrie-Hoppen C, Dworkin HJ. Repetitively negative changing T-waves at 24-h electrocardiographic monitors in patients with the chronic fatigue syndrome. Left ventricular dysfunction in a cohort. Chest. 1993;104:1417-1420.

62. Rowe PC, Bou-Holaigah I, Kan JS, et al. Is neurally medicated hypotension an unrecognized cause of chronic fatigue syndrome? Lancet. 1995;345:623-624.

63. Dworkin HJ, Lawrie-Hoppen C, Bohdiewiez P, et al. Abnormal left ventricular myocardial dynamics in eleven patients with the chronic fatigue syndrome. Clin Nuc Med. 1994;19:657-677.

64. Lerner AM, Goldstein J, Chang CH, et al. Cardiac involvement in patients with the chronic fatigue syndrome as documented with Holter and biopsy data in Birmingham, Michigan. Infect Dis Clin Pract. 1997;6:327-333.

65. Webster BH. Cardiac complications of infectious mononucleosis: a review of the literature and report of five cases. Am J Med Sci. 1957;234:62-70.

66. Tyson AA Jr, Hackshaw BT, Kutcher MA. Acute Epstein-Barr virus myocarditis simulating myocardial infarction with cardiogenic shock. South Med J. 1989;82:1184-1186.

67. Herbert MM, Yu C, Towbin JA, Rogers BB. Fatal Epstein-Barr virus myocarditis in a child with repetitive myocarditis. Fetal Pediatr Pathol. 1995; $15: 805-812$

68. LeBlanc MH, Boudriau S, Doyle D, et al. Epstein-Barr virus mediated graft rejection in heart transplant patients: implication of the cardiac cytoskeleton. Transplant Proc. 1998;30:918.

69. Lerner AM, Beqaj SH, Deeter RG, et al. IgM serum antibodies to human cytomegalovirus nonstructural gene products $\mathrm{p} 52$ and $\mathrm{C}_{\mathrm{M} 2}$ (UL44 and UL 57) are uniquely present in a subset of patients with chronic fatigue syndrome. In Vivo. 2002;16:153-160.

70. Beqaj SH, Lerner AM, Fitzgerald JT. Immunoassay with cytomegalovirus early antigens from gene products p52 and $\mathrm{CM}_{2}$ (UL44 and UL57) detects active infection in patients with chronic fatigue syndrome. J Clin Pathol. 2007;61:623-626.

71. Lerner AM, Zervos M, Chang CH, et al. A small randomized placebo controlled trial of the use of antiviral therapy for patients with chronic fatigue syndrome. Clin Infect Dis. 2004;32:1657-1658.

72. Lerner AM, Beqaj SH, Deeter RJ, et al. Valacyclovir treatment in Epstein-Barr virus subset chronic fatigue syndrome with long-term thirty-six month follow-up. In Vivo. 2007;21:707-714.

73. Jason LA, Richman JA, Rademaker AW, et al. A community-based study of chronic fatigue syndrome. Arch Intern Med. 1999;159:2129-2137.

74. Straus SE, Tosato G. Persisting illness and phase complete fatigue in adults with evidence of Epstein-Barr virus infections. Ann Intern Med. 1985;102:7-16.

75. Lombardi VC, Ruscette FW, Das Gupta J, et al. Detection of an infectious retrovirus XMRV in blood cells of patients with chronic fatigue syndrome. Science. 2009;326:585-589.

76. Kumar P, Abhik S, Robertson ES. Epstein-Barr virus hijacks cell-cycle machinery. Microbe. 2010;5:251-256.
Virus Adaptation and Treatment

\section{Publish your work in this journal}

Virus Adaptation and Treatment is an international, peer-reviewed open access journal focusing on the study of virology, viral adaptation and the development and use of antiviral drugs and vaccines to achieve improved outcomes in infection control and treatment. The journal welcomes original research, basic science, clinical \& epidemiological

\section{Dovepress}

studies, reviews \& evaluations, expert opinion and commentary, case reports and extended reports. The manuscript management system is completely online and includes a very quick and fair peer-review system, which is all easy to use. Visit http://www.dovepress.com/ testimonials.php to read real quotes from published authors. 